\title{
Effect of an Integrated Clinical Pharmacist on the Drivers of Provider Burnout in the Primary Care Setting
}

\author{
Jordan D. Haag, PharmD, Kaitlin J. Yost, PharmD, \\ Kimberly A. Kosloski Tarpenning, PharmD, Audrey J. Umbreit, PharmD, \\ Sarab A. McGill, PharmD, Amy L. Rantala, MD, James A. Storlie, MD, \\ Jay D. Mitchell, MD, Ross A. Dierkhising, MS, and Nilay D. Shah, PhD
}

Purpose: As the prevalence of provider burnout continues to increase, it is critical to identify interventions that may impact provider satisfaction, such as an integrated clinical pharmacist. This study aimed to assess the perceived effect of pharmacist integration on primary care provider satisfaction and drivers of provider burnout in the primary care setting.

Methods: A cross-sectional survey with 11 questions across 4 domains was distributed to primary care providers in a large integrated health system.

Results: of 295 providers invited to take the survey, 119 responded (40\% response rate). Most providers had worked with a pharmacist for at least 2 years and utilized them weekly or daily. At least $87 \%$ of provider respondents strongly agreed or somewhat agreed that the integrated clinical pharmacist reduced their workload by working directly with patients and non-provider staff, improved overall medication use, helped patients meet health goals and quality measures, and overall helped them to effectively manage their panel of patients. Providers found greater meaning in work through the presence of the clinical pharmacist, which allowed them more time to focus on professionally fulfilling aspects of their work and helped them feel less emotional exhaustion. Overall, $91 \%$ of providers were extremely satisfied with the clinical pharmacy service.

Conclusions: These findings may be used to justify the expansion of clinical pharmacy services in primary care to practice areas experiencing problems with 4 specific drivers of provider burnout: workload and job demands, efficiency and resources, meaning in work, and social support and community at work. (J Am Board Fam Med 2021;34:553-560.)

Keywords: Clinical Pharmacy Service, Cross-Sectional Studies, Health Personnel, Job Satisfaction, Occupational Burnout, Patient Care Team, Pharmacists, Practice Management, Primary Health Care, Surveys and Questionnaires, Workforce, Workload

\section{Introduction}

Burnout is a syndrome consisting of emotional exhaustion, cynicism, and diminished efficacy. ${ }^{1}$ More

This article was externally peer reviewed.

Submitted 17 November 2020; revised 19 January 2021; accepted 5 February 2021.

From the Department of Pharmacy, Mayo Clinic, Rochester, MN (JDH); Department of Pharmacy, Mayo Clinic Health System - Northwest Wisconsin region, Eau Claire, WI (KJY); Department of Pharmacy, Mayo Clinic Health System, Owatonna - Southeast Minnesota region, MN (KAKT); Department of Pharmacy, Mayo Clinic Health System Southwest Minnesota region, Mankato, MN (AJU); Avera Medical Group Brookings, Brookings, SD (SAM); Family Medicine, Mayo Clinic Health System - Northwest Wisconsin region, Eau Claire, WI (ALR, JAS); Department of Family Medicine, Mayo Clinic, Rochester, MN (JDM); Division of Biomedical Statistics and Informatics, Mayo Clinic, Rochester, MN (RAD); Division of Health Care Policy and Research, than half of US physicians report experiencing professional burnout. ${ }^{2}$ Given the high prevalence, many interventions have been assessed to help reduce burnout. A recent systematic review and meta-analysis reported that most interventions produce small, yet significant decreases in burnout. ${ }^{3}$ However, this small benefit has a larger treatment effect when executed with an organizationdirected approach. ${ }^{3}$ Shanafelt and Noseworthy ${ }^{4}$

Robert D. and Patricia E. Kern Center for the Science of Health Care Delivery, Mayo Clinic, Rochester, MN (NDS).

Funding: None.

Conflict of interest: None.

Prior presentation(s): None.

Corresponding author: Jordan D. Haag, PharmD, Department of Pharmacy, Mayo Clinic, 200 First St SW, Rochester, MN 55905 (E-mail: haag.jordan@mayo.edu). 
have outlined an organization-directed approach to help identify 7 key drivers of burnout and engagement, with the individual, work unit, organizational, and national factors that influence each driver.

The National Academy of Medicine recommends optimizing team-based care delivery to help reduce provider burnout. ${ }^{5}$ The focus of our investigation is on 1 specific member of the care team, the integrated clinical pharmacist. Existing literature describes the impact of clinical pharmacists on patient experience, ${ }^{6}$ improved population health, ${ }^{7-17}$ and reduced per-capita costs. ${ }^{18-23}$ However, less is known about the impact of pharmacist integration in the care team on provider burnout.

One study demonstrated high satisfaction and perceived benefit with clinical pharmacist services in primary care, but this study did not assess the potential impact of pharmacist integration in the care team on drivers of provider burnout or provide guidance for developing an organization-directed approach. ${ }^{24} \mathrm{~A}$ recent study used structured interviews to evaluate the effect of pharmacist integration on provider burnout, specifically the effects of delivery of comprehensive medication management on the primary care provider's work life. ${ }^{25}$ The qualitative findings of that study suggested that pharmacist integration may result in decreased workload, increased patient satisfaction, decreased mental exhaustion, enhanced professional learning, increased provider access, and achievement of quality measures. ${ }^{25}$ However, that time-intensive study method has limited feasibility for determining external validity at other organizations. To our knowledge, no method currently exists to evaluate the influence of pharmacist integration on key drivers of provider burnout. This study aimed to assess the effect of an integrated clinical pharmacist on the key drivers of provider burnout in the primary care setting through a survey of providers.

\section{Methods}

This cross-sectional electronic survey was conducted at a single integrated health system in 2 states as a means of improving quality. The family medicine and internal medicine providers invited to participate represented 4 distinct geographic regions (Southeast Minnesota, Southwest Minnesota, Northwest Wisconsin, and Southwest Wisconsin) including both urban and rural practice locations.
Five of the investigators (JDH, KJY, KAKT, AJU, and SAM) developed the survey content by using the framework of an existing unpublished provider satisfaction survey. Four of the 7 key driver domains of provider burnout, as outlined by Shanafelt and Noseworthy, ${ }^{4}$ were selected to evaluate the effect of an integrated clinical pharmacist: workload and job demands, efficiency and resources, meaning in work, and social support and community at work. The physician investigators (ALR, JAS, and JDM) tested and reviewed the survey to optimize question content and assess feasibility. Specifically, this critique requested feedback on the clarity of both questions and answer choices, to identify any missing questions or issues with questions, and the length of time required to complete the survey.

\section{Recruitment}

A survey invitation was sent via e-mail with a cover letter describing the survey on November 5, 2019, with electronic reminders sent 7 and 14 days later. The survey was closed to participants after 21 days. The Mayo Clinic Institutional Review Board determined that this assessment did not require formal review.

\section{Setting and Participants}

The providers surveyed were physicians and advanced practice providers (APPs), namely nurse practitioners and physician assistants, working in primary care clinics in which an integrated clinical pharmacist had been part of the health care team for 12 months or longer. The clinical pharmacist team integrated within the survey practice sites includes 16 pharmacists representing 11.4 full-time equivalents (FTEs). The practice model for this team is comprehensive medication management, as outlined by the Patient-Centered Primary Care Collaborative, and includes a periodic peer-review process to ensure fidelity to the model. ${ }^{26}$ Our credentialed clinical pharmacists use collaborative practice agreements when appropriate per state laws, to make prescriptive changes to medication therapy, including starting, stopping, or modifying medications and ordering laboratory tests for monitoring of safety and efficacy.

Providers within these clinics were invited to participate if they maintained at least 0.2 FTE dedicated to direct patient care. This FTE threshold was selected to ensure that the surveyed provider could accurately evaluate the effect of clinical 
pharmacist collaboration. The amount of FTE dedicated to patient care was estimated by calculating a 6-month average. Resident physicians and fellows were excluded from the provider population used in this study because of expected turnover. However, staff provider residency preceptors for the medical residency programs were included, regardless of FTE dedicated to direct patient care.

\section{Measures}

The survey contained 11 questions total (Supplemental Material), with 6 questions aimed at capturing provider characteristics, including department or division, provider type, practice area, duration of pharmacist collaboration, and self-reported age and sex. Two questions assessed provider utilization of the integrated clinical pharmacist through measurement of the frequency of utilization and type of collaboration activity. We defined collaboration activities as chronic disease management, chart review or electronic consultation, comprehensive medication management, clinic staff drug education, care transition management, curbside consultation, same-day patient education, quality improvement initiatives, or others. One question contained 10 targeted sub-questions to assess the effect of the integrated clinical pharmacist on provider burnout by using a Likert scale with 5 response categories ranging from "strongly agree" to "strongly disagree." The survey included an option to provide free-text feedback or concerns regarding clinical pharmacist integration into the primary care practice. Three of the descriptive questions (13 total targeted sub-questions) were mapped to 1 of the key drivers of burnout and engagement, as described by Shanafelt and Noseworthy ${ }^{4}$ : workload and job demands, efficiency and resources, meaning in work, and social support and community at work.

\section{Analysis}

The survey responses were reported as frequencies and percentages. Associations between questions were assessed with the Pearson $\chi^{2}$ test.

\section{Results}

\section{Characteristics of Providers}

Of the 295 providers invited to participate in the study survey, 119 responded, for a response rate of $40 \%$. The providers represented the Department of Family Medicine ( $n=86 ; 72 \%$ with a $44 \%$ response rate), Division of Community Internal
Medicine ( $\mathrm{n}=29 ; 24 \%$ with a $40 \%$ response rate), and the Division of General Internal Medicine ( $\mathrm{n}=$ $4 ; 3 \%$ with a $15 \%$ response rate). Differences in geographic region response rates ranged from $32 \%$ to $63 \%$. Physicians accounted for $69 \%(\mathrm{n}=82)$ of provider respondents, and $31 \%(\mathrm{n}=37)$ were APPs. In the practice sites surveyed (excluding medical residency program sites), there was an average of 10 physicians (range, 5-18) and 7 APPs (range, 2 to 14). The age of respondents was distributed with 42 respondents $(37 \%)$ between 31 and 40 years, 36 (31\%) between 41 and 50 years, $26(23 \%)$ between 51 and 60 years, and $11(10 \%)$ either 30 years or younger or 60 years or older (4 did not provide their age). Most respondents were women ( $\mathrm{n}=73$; 63\%; 4 missing sex). Most respondents ( $\mathrm{n}=71$; $61 \%$ ) reported working with an integrated clinical pharmacist in their current practice site for 2 to 5 years, with 27 (23\%) working with a pharmacist for less than 2 years, and 18 (16\%) for more than 5 years ( 3 provided responses of "I do not know" or were missing).

\section{Pharmacist Utilization}

Most providers reported using the pharmacist weekly ( $\mathrm{n}=64 ; 54 \%)$, with $24(20 \%)$ using the pharmacist daily and $9(8 \%)$ multiple times daily. Providers used the pharmacist in various roles to assist in their clinical practice (Figure 1). The mostreported collaboration activities were curbside consultations, chronic disease management, and comprehensive medication management. The frequency of utilization was similar between APPs and physicians $(P=.19)$ and between family medicine and internal medicine providers $(P=.97)$ as shown in Supplemental Material.

\section{Influence of Pharmacists}

The Table 1 outlines the 10 targeted survey subquestions used to assess the effects of the integrated clinical pharmacist on provider burnout mapped to 4 of the 7 key drivers of burnout and engagement. These questions focused on the effect of a pharmacist on the provider's ability to provide high-quality patient care. For all questions, most providers agreed or strongly agreed that the pharmacists provided a positive effect.

\section{Satisfaction With Pharmacist}

Most providers were extremely satisfied with the clinical pharmacy service $(91 \%, 105$ of 116$)$. Of the 
119 respondents, 57 provided additional commentary or feedback regarding their experience with the integrated clinical pharmacist.

\section{Discussion}

The results of this survey demonstrate that pharmacist involvement in the health care team may positively influence 4 key drivers of provider burnout: workload and job demands, efficiency and resources, meaning in work, and social support and community at work. $^{4}$

For the workload and job demands driver of provider burnout and engagement, our results suggest a strong benefit of including clinical pharmacists in the health care team. More than $95 \%$ of providers indicated that pharmacists are a critical component of the health care team, with 1 perceived benefit suggested as a decrease in workload. The perceived decrease in workload could be related to the noted decrease in time spent answering patient questions with pharmacist involvement. One study indicated that clinical pharmacists spend an average of 1.6 hours per day assisting providers with nonvisit patient care activities. ${ }^{27}$ Multiple providers commented that clinical pharmacist inclusion decreased their workload by assisting with general patient care, quality of patient care, and access limitations within primary care.

For the efficiency and resources driver of provider burnout and engagement, numerous providers commented that having clinical pharmacy services available to assist with questions or discuss clinical scenarios was an important resource in their practice. Survey responses further described the effect of the clinical pharmacy resource, with more than $90 \%$ of providers agreeing that clinical pharmacy services help patients progress toward health goals, improve quality measures, and assist with effective panel management. Improvement in medication utilization, medication knowledge, and education were some of the benefits of working with a clinical pharmacist noted in the invited comments for feedback.

Regarding the social support and community at work driver of provider burnout and engagement, providers agreed that co-management of complex patients with the pharmacist-led to less emotional exhaustion. With an aging population and increasing numbers of patients with multiple comorbid conditions and polypharmacy, care management for complex patients is becoming an increasing aspect of primary care. Sharing that burden with professionals with expertise in managing complex medication regimens is important. This also parallels the findings of Funk and colleagues, in which providers noted that pharmacist services "decreased some of the pressure and mental/emotional burden of taking care of complex patients." 25 Multiple providers commented about the positive impact of the clinical pharmacist on their practice (eg, quality, safety, and education) and that they could not imagine working without a pharmacist on the care team.

For the meaning in work driver of provider burnout and engagement, providers reported that pharmacist involvement allows providers to focus more on patient care and professional development. A majority (91\%) of providers were extremely satisfied with clinical pharmacy services. This is consistent with a previous study demonstrating a high degree of satisfaction and perceived benefit with clinical pharmacist services in primary care. ${ }^{24}$ As administrative burdens continue to increase for providers in primary care, sharing this burden with care team members that are best equipped to assist with specific issues, such as medication-related concerns, allows providers to focus on areas of their role they may find more personally satisfying.

An unforeseen theme arose when reviewing provider commentary about access to clinical pharmacy services. Providers indicated benefits from clinical pharmacy services that seemed to correlate with ease of access to the clinical pharmacist. Multiple providers reported appreciation with being able to easily access the clinical pharmacist for curbside consults, clinical discussions, and medication questions. For most providers, easy access was described in both physical location and timely access to the clinical pharmacist. A recent study of clinical pharmacist nonvisit care activities found that pharmacists are most often used for face-to-face curbside consults rather than inbox messages or telephone calls. ${ }^{27}$ The discussion of access to clinical pharmacy services often included a desire for an increase in both the amount and availability of this resource.

Despite the potential multidimensional impact of clinical pharmacists on health care delivery, 1 barrier to expansion is limited fee-for-service revenue-generating opportunities. Pharmacists are not currently recognized as qualified health care professionals by the Centers for Medicare \& 
Table 1. Survey Responses: Effects of Integrated Pharmacists on Drivers of Burnout ( $n=113)$

\begin{tabular}{|c|c|c|c|c|c|}
\hline \multirow[b]{2}{*}{ Survey Sub-question } & \multicolumn{5}{|c|}{ Response* $^{*}$} \\
\hline & $\begin{array}{l}\text { Strongly } \\
\text { Agree }\end{array}$ & $\begin{array}{l}\text { Somewhat } \\
\text { Agree }\end{array}$ & $\begin{array}{l}\text { Neither Agree } \\
\text { nor Disagree }\end{array}$ & $\begin{array}{l}\text { Somewhat } \\
\text { Disagree }\end{array}$ & $\begin{array}{l}\text { Strongly } \\
\text { Disagree }\end{array}$ \\
\hline \multicolumn{6}{|l|}{ Workload and job demands } \\
\hline $\begin{array}{l}\text { The clinical pharmacist is } \\
\text { working together with other } \\
\text { non-PCP members of our } \\
\text { clinic team, and this results in } \\
\text { my workload decreasing. }\end{array}$ & $75(66)$ & $24(21)$ & $9(8)$ & $1(1)$ & $4(4)$ \\
\hline $\begin{array}{l}\text { The integrated clinical } \\
\text { pharmacist support is a critical } \\
\text { component of the health care } \\
\text { team structure. }(\mathrm{n}=112)\end{array}$ & $97(87)$ & $11(10)$ & $1(1)$ & $1(1)$ & $2(2)$ \\
\hline $\begin{array}{l}\text { Working with the clinical } \\
\text { pharmacist results in a } \\
\text { decreased amount of time I } \\
\text { spend answering patient } \\
\text { questions during nonvisit care } \\
\text { time. }\end{array}$ & $73(65)$ & $27(24)$ & $8(7)$ & $1(1)$ & $4(4)$ \\
\hline \multicolumn{6}{|l|}{ Efficiency and resources } \\
\hline $\begin{array}{l}\text { Clinical pharmacy services have } \\
\text { improved overall medication } \\
\text { use within my practice. }\end{array}$ & $91(81)$ & $16(14)$ & $3(3)$ & $0(0)$ & $3(3)$ \\
\hline $\begin{array}{l}\text { Patients who work with our } \\
\text { clinical pharmacist make } \\
\text { progress towards their health } \\
\text { goals. }\end{array}$ & $90(80)$ & $19(17)$ & $2(2)$ & $0(0)$ & $2(2)$ \\
\hline $\begin{array}{l}\text { Clinical pharmacy services } \\
\text { improve our clinic's ability to } \\
\text { meet health care quality } \\
\text { measures. }\end{array}$ & $91(81)$ & $15(13)$ & $4(4)$ & $1(1)$ & $2(2)$ \\
\hline $\begin{array}{l}\text { Clinical pharmacy services have } \\
\text { helped to more effectively } \\
\text { manage my panel of patients. } \\
(\mathrm{n}=112)\end{array}$ & $84(75)$ & $17(15)$ & $6(5)$ & $2(2)$ & $3(3)$ \\
\hline \multicolumn{6}{|l|}{ Meaning in work } \\
\hline $\begin{array}{l}\text { Integration of a clinical } \\
\text { pharmacist in my practice } \\
\text { allows me to focus more on } \\
\text { patient care and other } \\
\text { activities that I find } \\
\text { professionally fulfilling. }\end{array}$ & $79(70)$ & $24(21)$ & $5(4)$ & $2(2)$ & $3(3)$ \\
\hline $\begin{array}{l}\text { Clinical pharmacy services at my } \\
\text { site has increased my } \\
\text { opportunities for professional } \\
\text { development. }\end{array}$ & $64(68)$ & $23(20)$ & $20(18)$ & $1(1)$ & $5(4)$ \\
\hline \multicolumn{6}{|l|}{$\begin{array}{l}\text { Social support and community } \\
\text { at work }\end{array}$} \\
\hline $\begin{array}{l}\text { I feel less emotional exhaustion } \\
\text { when I co-manage complex } \\
\text { patients with the clinical } \\
\text { pharmacist. }\end{array}$ & $77(68)$ & $23(20)$ & $9(8)$ & $0(0)$ & $4(4)$ \\
\hline
\end{tabular}

PCP, primary care provider.

*Values are number $(\mathrm{N})$ and percentage (\%) of respondents.

Used with permission of Mayo Foundation for Medical Education and Research.

Medicaid Services and thus are limited to indirect billing methods (chronic care management, billing incident to the provider). Despite expanded coverage for medication therapy management billing codes among some state Medicaid plans, self- insured employer groups, or regional health plans, the fee-for-service revenue generation for a clinical pharmacist remains limited. One additional challenge for smaller practice sites is how to integrate clinical pharmacist services without requiring an 
Figure 1. Provider Reasons for Pharmacist Utilization for Collaboration Activities, $(n=119)$.

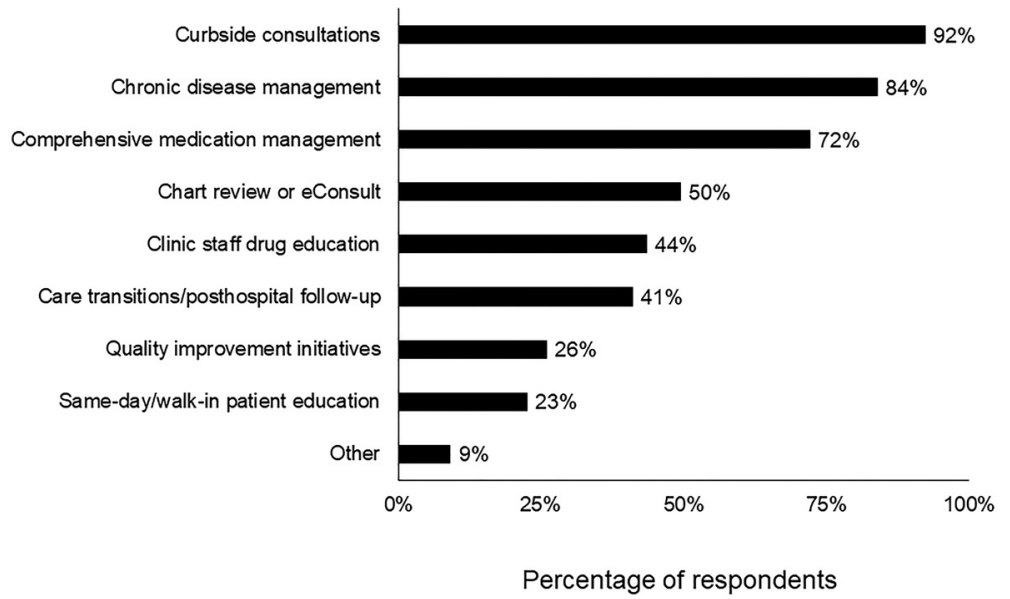

entire FTE, which highlights the need for developing innovative collaborative practice models.

\section{The Provider Perspective}

During the discussion of the survey results, the provider investigators echoed similar themes of the collaboration with clinical pharmacists increasing value of care for patients and impacting drivers of burnout. As the payment models evolve to more metricdriven care and patient panel sizes increase, the provider investigators recognize that this collaboration allows providers the ability to individualize patient care while ensuring metrics are met. As patients live longer and their illnesses become more complex, providers can easily feel overwhelmed by the technical details of patient medication regimens. In this respect, clinical pharmacist involvement as a multidimensional resource can assist to manage those technical questions regarding safety and value, in addition to providing direct patient care management. We believe that this collaboration improved their meaning in their work, improved the quality of care for patients, and allowed patients to engage more with their own care.

The strengths of this study include an adequate response rate and providers that represented a broad range of primary care providers within the practice. Providers represented both physicians and APPs in family medicine and internal medicine and were distributed across various ages and sexes.

This survey of outpatient primary care providers is limited by the lack of comparative published literature for external validation of findings. In addition, no comparator group was used in this study because only providers who had access to pharmacist resources were surveyed. Nonresponse bias also may have been present because providers with incredibly positive or very negative views of pharmacist involvement may be more likely to respond to the survey. In addition, the use of a survey in a provider cohort that may be actively experiencing burnout may contribute to non-response bias, given competing duties and time constraints.

External validity to other health systems may be limited given that the study was performed at a single institution; however, the involved practice sites represent diverse providers practicing in both urban and rural areas. The potential practice site variation may represent both a strength and a limitation given the heterogeneity in type and level of services provided by pharmacists in different practice sites, even within the same institution. Individual clinic sites surveyed varied by populations served, length of time pharmacists were embedded, access to other specialties and resources, physical layout and physical access to the pharmacist, and amount of time pharmacists were present in the clinic.

Future areas of study include how specific factors, including the type of pharmacist utilization, level of involvement, the strength of personal and professional relationships, ease of access to pharmacists, and pharmacist FTE per patient panel size affect the magnitude of effect on provider burnout.

\section{Conclusion}

This survey of primary care providers demonstrated that the presence of pharmacists embedded in the 
health care team may impact drivers of provider burnout. Results of this study may be used as part of a comprehensive organizational strategy for provider burnout and engagement, specifically affecting 4 key driver domains of provider burnout and engagement: workload and job demands, efficiency and resources, meaning in work, and social support and community at work.

The Mayo Midwest Pharmacy Research Committee (Mayo Clinic, Rochester, Minnesota) provided discretionary funding support for the investigator team. The Survey Research Center (Mayo Clinic, Rochester, Minnesota) assisted with the design and execution of the survey.

To see this article online, please go to: http://jabfm.org/content/ 34/3/553.full.

\section{References}

1. Maslach C, Schaufeli WB, Leiter MP. Job burnout. Annu Rev Psychol 2001;52:397-422.

2. Shanafelt TD, Hasan O, Dyrbye $L N$, et al. Changes in burnout and satisfaction with work-life balance in physicians and the general US working population between 2011 and 2014. Mayo Clin Proc 2015;90:1600-13.

3. Panagioti $M$, Panagopoulou $E$, Bower $P$, et al. Controlled interventions to reduce burnout in physicians: a systematic review and meta-analysis. JAMA Intern Med 2017;177:195-205.

4. Shanafelt TD, Noseworthy JH. Executive leadership and physician well-being: nine organizational strategies to promote engagement and reduce burnout. Mayo Clin Proc 2017;92:129-46.

5. Smith CD, Balatbat $C$, Corbridge $S$, et al. National Academy of Medicine. Implementing optimal team-based care to reduce clinician burnout. NAM Perspectives 2018;8.

6. Giberson S, Yoder S, Lee MP. Improving Patient and Health System Outcomes through Advanced Pharmacy Practice. A Report to the U.S. Surgeon General. 2011. Available from: https://www.accp. com/docs/positions/misc/improving_patient_and_ health_system_outcomes.pdf. Accessed April 26, 2021.

7. Carter BL, Ardery G, Dawson JD, et al. Physician and pharmacist collaboration to improve blood pressure control. Arch Intern Med 2009;169:19962002.

8. Choe HM, Mitrovich S, Dubay D, Hayward RA, Krein SL, Vijan S. Proactive case management of high-risk patients with type 2 diabetes mellitus by a clinical pharmacist: a randomized controlled trial. Am J Manag Care 2005;11:253-60.

9. Cohen LB, Taveira TH, Khatana SA, Dooley AG, Pirraglia PA, Wu WC. Pharmacist-led shared medical appointments for multiple cardiovascular risk reduction in patients with type 2 diabetes. Diabetes Educ 2011;37:801-12.

10. Hunt JS, Siemienczuk J, Pape G, et al. A randomized controlled trial of team-based care: impact of physician-pharmacist collaboration on uncontrolled hypertension. J Gen Intern Med 2008;23:1966-72.

11. Ip EJ, Shah BM, Yu J, Chan J, Nguyen LT, Bhatt DC. Enhancing diabetes care by adding a pharmacist to the primary care team. Am J Health Syst Pharm 2013;70:877-86.

12. Johnson KA, Chen S, Cheng IN, et al. The impact of clinical pharmacy services integrated into medical homes on diabetes-related clinical outcomes. Ann Pharmacother 2010;44:1877-86.

13. Lee JK, Grace KA, Taylor AJ. Effect of a pharmacy care program on medication adherence and persistence, blood pressure, and low-density lipoprotein cholesterol: a randomized controlled trial. JAMA 2006;296:2563-71.

14. Vivian EM. Improving blood pressure control in a pharmacist-managed hypertension clinic. Pharmacotherapy. 2002;22:1533-40.

15. Bellone JM, Barner JC, Lopez DA. Postdischarge interventions by pharmacists and impact on hospital readmission rates. J Am Pharm Assoc (2003) 2012;52:358-62.

16. Butler A, Dehner M, Gates RJ, et al. Comprehensive Medication Management Programs: Description. Impacts, and Status in Southern California 2015;2015. Available from: https://calrightmeds.org/wp-content/ uploads/2019/04/CMMWhitePaperCDPH2015Dec 23FINALrev.pdf. Accessed April 29, 2021.

17. Cavanaugh JJ, Jones CD, Embree G, et al. Implementation science workshop: primary carebased multidisciplinary readmission prevention program. J Gen Intern Med 2014;29:798-804.

18. Isetts BJ, Schondelmeyer SW, Artz MB, et al. Clinical and economic outcomes of medication therapy management services: the Minnesota experience. J Am Pharm Assoc 2008;48:203-14.

19. Pellegrin KL, Krenk L, Oakes SJ, et al. Reductions in medication-related hospitalizations in older adults with medication management by hospital and community pharmacists: a quasi-experimental study. J Am Geriatr Soc 2017;65:212-9.

20. Perlroth D, Marrufo G, Montesinos A, et al. Medication Therapy Management in Chronically Ill Populations: Final Report. 2013. Available from: https://innovation.cms.gov/files/reports/mtm_final_ report.pdf. Accessed April 26, 2021.

21. Polinski JM, Moore JM, Kyrychenko P, et al. An insurer's care transition program emphasizes medication reconciliation, reduces readmissions and costs. Health Aff (Millwood) 2016;35:1222-9.

22. Ramalho de Oliveira D, Brummel AR, Miller DB. Medication therapy management: 10 years of experience in a large integrated health care system. J Manag Care Pharm 2010;16:185-95. 
23. Smith M, Giuliano MR, Starkowski MP. In Connecticut: improving patient medication management in primary care. Health Aff (Millwood) 2011;30:646-54.

24. Truong H, Kroehl ME, Lewis C, et al. Clinical pharmacists in primary care: provider satisfaction and perceived impact on quality of care provided. SAGE Open Med 2017;5:2050312117713911.

25. Funk KA, Pestka DL, Roth McClurg MT, Carroll JK, Sorensen TD. Primary care providers believe that comprehensive medication management improves their work-life. J Am Board Fam Med 2019;32:462-73.
26. Patient-Centered Primary Care Collaborative (PCPCC). The Patient-Centered Medical Home: Integrating Comprehensive Medication Management to Optimize Patient Outcomes Resource Guide. 2012. Available from: https://www.pcpcc.org/sites/ default/files/media/medmanagement.pdf. Accessed January 18, 2021.

27. Kosloski Tarpenning KA, McGill SA, Peterson JA, Yost KJ, Tumerman MD. Quantitative analysis of nonvisit care activities performed by ambulatory care pharmacists in the outpatient primary care clinic setting. J Am Coll Clin Pharm 2019; 2:645-51. 